\title{
Mobilizing Climate Finance for Clean Energy and Energy \\ Efficiency Investments: A Primer for Integration into USAID Energy
}

\author{
Sector Activities
}

\section{What Is Climate Finance?}

In the context of USAID energy programming, climate finance refers to the provision or mobilization of financial resources to assist developing countries in drawing down greenhouse gas (GHG) emissions while building energy sector resilience and adapting to the impacts of climate change.

There are several methods for climate finance, performed by diverse stakeholders. Grants, loans, loan guarantees, bonds, equity investments, and other funds for clean energy investments - as well as specialized climate finance facilities, such as the Global Environment Facility and the Green Climate Fund are all examples. Additional mechanisms include technical assistance, training, and capacity building programs that enable partners to mobilize funding from the public and private sectors.

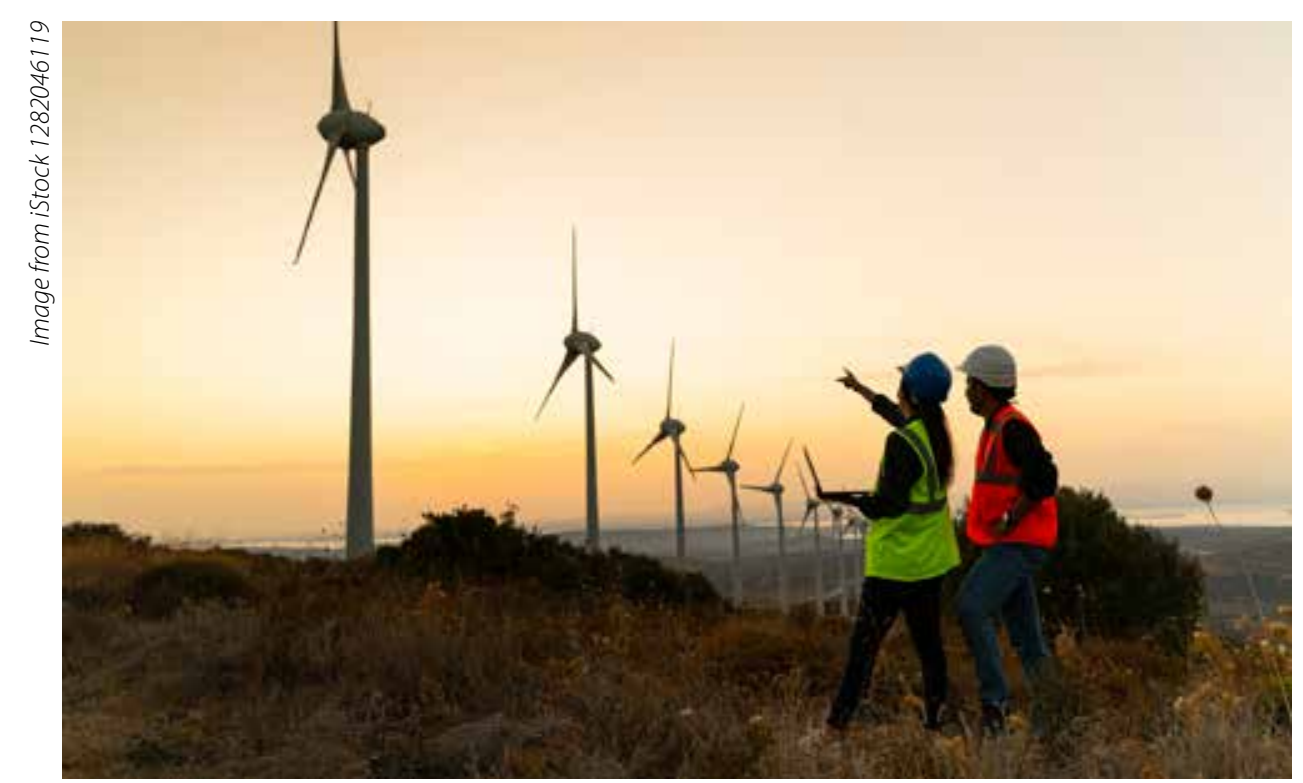

Climate finance is foundational in realizing the decarbonization targets each country has committed to in their Nationally Determined Contributions (NDCs) under the 2015 Paris Agreement. The International Energy Agency (IEA) calculated that clean energy investment in developing countries needs to expand by more than seven times, to above $\$ 1$ trillion per year by the end of the 2020s, to put the world on track to reach net-zero emissions by 2050 .

\section{Assessing the Opportunities}

The primary purpose of this document, and the full assessment from which its content is derived, is to assist USAID staff in identifying opportunities for designing new interventions that integrate climate finance into their existing/planned energy sector programming. USAID staff are encouraged to review the various examples presented to determine whether any aspect of the proposed approach is applicable to the countries/regions in which they operate.

USAID engaged the U.S. Department of Energy's National Renewable Energy Laboratory (NREL) from May through August 2021 to conduct a short-term assessment of potential areas where USAID could strengthen its climate finance for clean energy programming. NREL first analyzed current trends in this sector, with a particular focus on impacts of the COVID-19 pandemic and the correlating economic downturn. NREL also interviewed several climate finance and clean energy experts and convened a targeted stakeholder workshop to identify opportunities. This document represents a high-level summary of the findings.

\section{Access the full report to learn more.}

\section{Climate Finance Trends}

Although the number of policies related to climate change and renewable energy generally increased across the world in 2020, countries still have much work to do in shaping and enforcing these policies with a whole-of-economy approach.

As noted, the overall investment picture is currently bleak; however, there are some bright spots. For example, corporate clean energy procurement has continued to

1 IEA (2021), IEA Publications. Financing Clean Energy Transitions in Emerging and Developing Economies. Accessed at: https://iea.blob.core. windows.net/assets/6756ccd2-0772-4ffd-85e4b73428ff9c72/FinancingCleanEnergyTransitionsinEMDEs_WorldEnergyInvestment2021SpecialReport.pdf. 


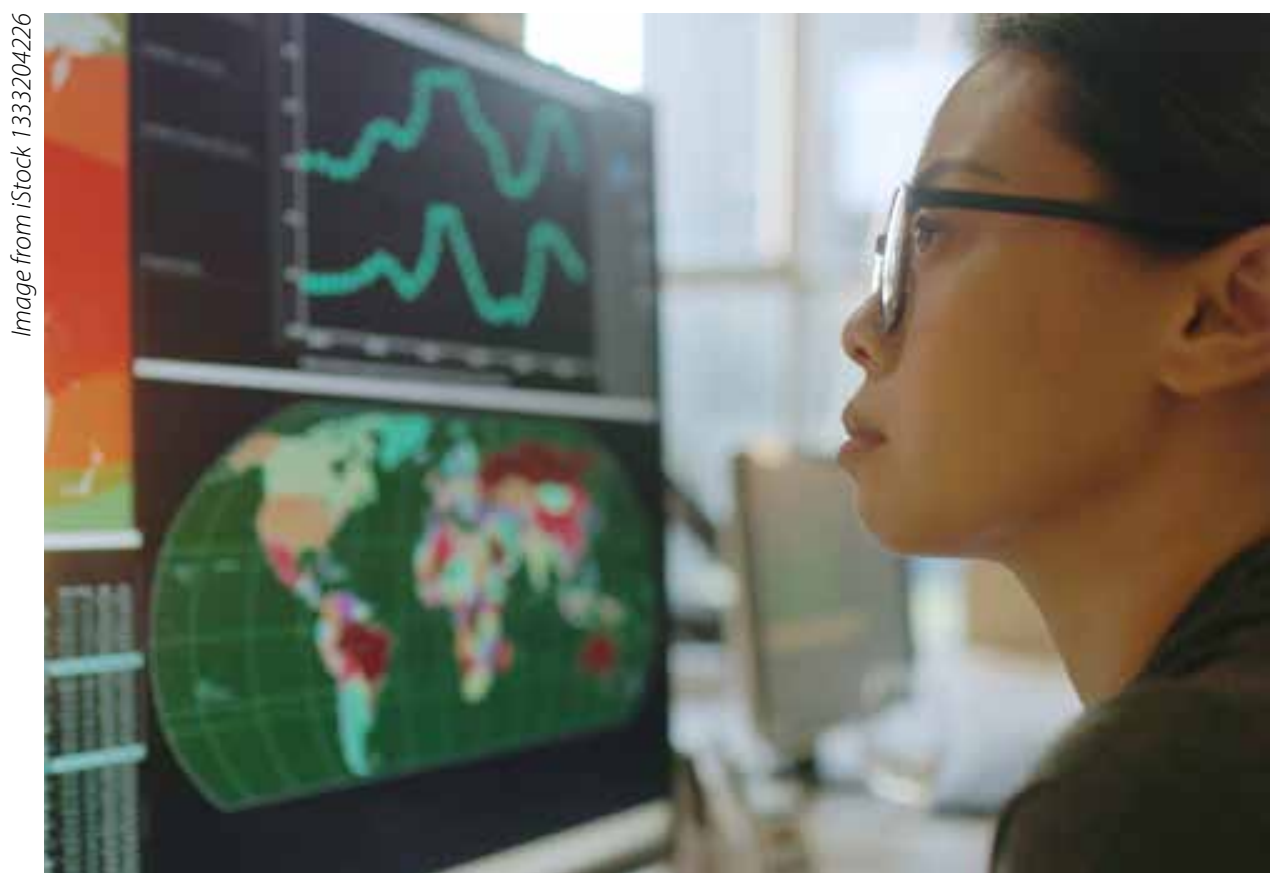

increase quickly, and participants have diversified both in terms of subsector (such as heavy industry) and emissions scope, with more corporations making value chain emissions reductions for supply chains a greater priority. Additionally, the financial sector has accelerated the mainstreaming of climate risk, enabling more investment from large sources of finance such as asset managers, institutional investors, and central banks. Investments in research and development and innovation in technologies and business models continue, with ever-increasing interest in opportunities such as battery energy system storage and green hydrogen. Thus, while COVID-19 negatively impacted public coffers, increased momentum in investment and innovation in the private sector offers promise for a climate finance approach centered on leveraging private sector capital.

Currently, 42 countries have submitted long-term strategy documents to the United Nations Framework Convention on Climate Change (UNFCCC), communicating their short- and medium-term actions toward ambitious net-zero goals. However, only seven of these submissions came from developing countries. Despite the multitude of domestic and donor-funded NDC support programs, many countries lack the capacity to translate their NDCs into robust, actionable investment strategies for systemic interventions and/or do not have a mechanism for connecting NDCs with longer-term strategies.

The most prevalent use of climate finance in developing countries is investment in one-off renewable energy projects. However, only by moving upstream to a coordinated approach of regulatory strengthening and long-term capacity development can climate finance enact change on the necessary timescale. This paradigm shift will maximize effective use of scarce public funding and improve the enabling environment to derisk private investment in developing countries. Finally, program designers must work with local investors and financiers, who have much better on-the-ground economic and social knowledge along with a stake in their communities. Additionally, broader stakeholder groups need to be engaged to ensure that the viewpoints of local communities are understood, enabling program designers to identify solutions that benefit marginalized groups who are also most affected by climate change.

\section{Climate Finance Levers}

NREL has identified 10 climate finance levers USAID could potentially apply to increase the scale of investment in clean energy and energy efficiency in partner countries. The levers, which fall into three themes, can be refined and developed into a suite of services that respond to regional and local climate finance barriers, opportunities, and priorities. The levers are not fully independent - combining multiple levers could maximize impact. Some levers are top-down measures that could result in significant clean energy deployment and GHG reductions, whereas the more bottom-up measures place a greater focus on people, capacity development, and social impacts.

\section{Innovation Highlight: Bulk Energy Efficiency Procurements}

USAID implementing partners can make aggregated procurements to create economies of scale and lower costs for new energy and energy efficiency technologies that are not yet deployed at significant levels. Options include heat pumps, industrial motors, clean energy mini-grids, solar plus behind-the-meter storage, and energy efficient LED lighting.

Recognizing the importance of cooling and the consequent energy use early on, USAID, in partnership with several organizations and the Government of India, has launched and mainstreamed a new class of superefficient air conditioners (ACs), with 30\% lower energy use compared to the best available in the market and with low global warming potential and zero ozone depletion potential refrigerants. The initial procurement of 100,000 ACs resulted in lowering the price of superefficient ACs to be cost-effective and an affordable choice for most customers. This was followed by more procurements and inclusion of such climate-friendly superefficient ACs in the public procurement portal as a standard option. 
Project Pipeline Levers

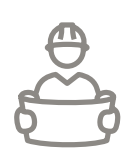

Promoting strategies that yield lower financing costs and reduce risks for investing in clean energy and energy efficiency projects

Barriers addressed: There is a shortage of high quality, investment ready clean energy/energy efficiency projects; and there are insufficient channels and intermediaries to connect investments with opportunities.

\section{- Lever One: Blended Finance to Catalyze Projects and Companies and Provide Utility Refinancing.}

With partners such as U.S. International

Innovation Highlight: Reverse

\section{Auctions}

Renewable energy auctions, including reverse auctions, have been used to support competitive procurements of bulk renewable energy power in several markets. For example, in October 2021, Colombia held its third round of renewable energy auctions, which awarded contracts for $800 \mathrm{MW}$ of solar generation at prices 15\% the market rate. These projects are expected to result in $\$ 850$ million of investment and displace 465,000 tons of carbon dioxide equivalent. USAID continues to provide auction design support to Colombia. More information can be found on $\underline{\text { USAID's Renewable Energy Auction }}$ Toolkit website.

Reverse auctions can also be used to support early retirement of coal plants. In the case of coal plant retirement, the winning bidder receives financing to replace coal assets with clean energy capacity. Then they can use the revenues from selling clean energy to pay off previous coal plant debts. At the same time, a third-party verifier can provide carbon credits for replacing the coal plant with clean energy, which the owner can then present to the government or development finance institutions (DFIs) for additional revenue, further incentivizing participation from coal asset owners.
Development Finance Corporation or through blended finance mechanisms such as Climate Investor One, USAID can provide project preparation and derisking support, use USAID's convening power to bring in more investors to scale financial resources, and consider supporting the riskier and/or emerging technology solutions. When solar developer CrossBoundary Energy was looking to enter the market in Sub-Saharan Africa, USAID provided a $\$ 1.3$ million grant that would require repayment only if the project was successful. That project ultimately attracted \$17.5 million in debt and equity.

\section{- Lever Two: Capacity Development to} Scale Project Pipelines and Improve Access to Climate Finance. Technical advisors can help public sector partners identify projects, conduct feasibility assessments, structure finance models, access investors and banks, and successfully apply for capacity development programs for their clean energy pipeline. In Mexico, USAID used a Global Development Alliance with financial firm Evensen Dodge to support states and municipalities with bundling small clean energy projects into portfolios of $\$ 100$ million to attract institutional investors.

\section{- Lever Three: Clean Energy Contract Standardization and Support for} Securitization to Increase Liquidity. Support multistakeholder efforts to create regional or subregional frameworks for asset-backed securitization. Provide guidance in developing standardized energy savings performance contracts, power purchase agreements (PPAs), solar, mini-grids, and other contracts that adhere to international investor standards, and provide capacity development for entrepreneurs to implement standards upstream. The World Bank Scaling Solar program, which USAID is partnered with through
Power Africa, creates a one-stop shop with standard PPAs and financial tools and services for the purpose of making privately funded, grid-connected solar photovoltaic projects cost competitive.

Policy and Infrastructure Levers

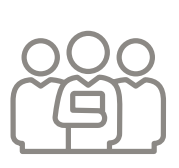
Supporting government ministries and regulators to open channels for sustained investment

Barriers addressed: Stimulus spending on clean energy is falling short of what is needed to ensure post-COVID-19 economic recovery; a net-zero-emissions-by-2050 pathway requires significantly strengthening clean energy and climate policies; NDCs and long-term strategies do not yet sufficient support the private sector in identifying investment opportunities or identify pathways to alleviating private sector investment contraints.

- Lever Four: Development of Public and Infrastructure Investments for Sustained Growth. Support development of green recovery packages or other governmentfunded efforts that use clean energy enablers to quick-start, inclusive job growth, e.g., technical assistance on design of return/rebate programs for inefficient appliances and equipment, clean energy funds, weatherization programs, and utility on-bill financing. Complete jobs, economic, and social analysis to determine priority programs and complement them with technical assistance and capacity development assistance. In partnership with USAID, the U.S. Department of Energy's Lawrence Berkeley National Laboratory worked with the South African Department of Mineral Resources and Energy in conducting a study assessing the impact of South Africa's Appliance Energy Efficiency Standards and Labeling Program on energy savings and mitigation of GHG emissions. 


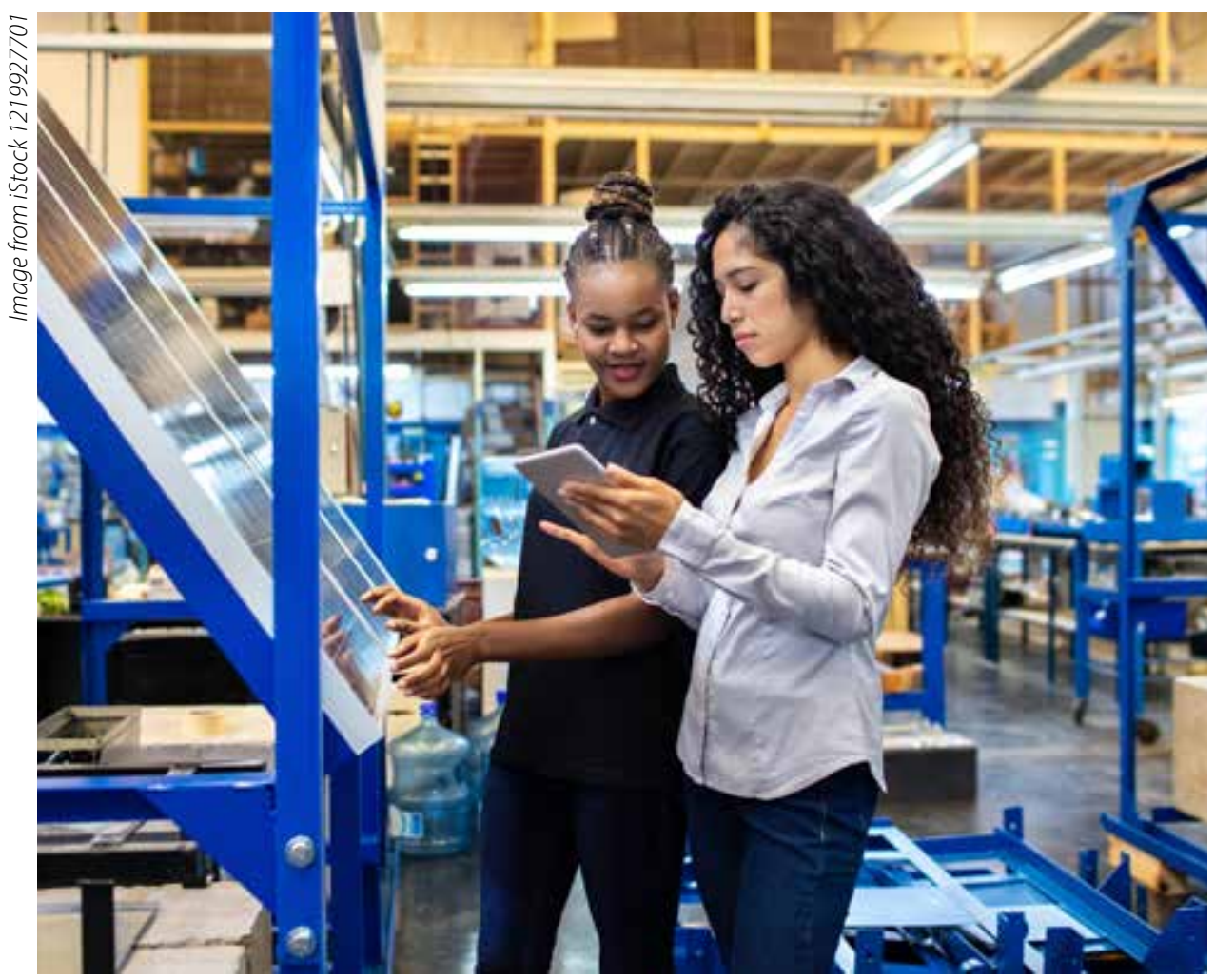

- Lever Five: Improvements to Enabling Environments to Attract Long-Term, Private Sector Investment. Use USAID's strong policy and decision-support expertise to create a sustainable environment for change. Support Integrated Resource and Resilience Planning (IRRPs), streamlined grid access procedures, and removal/reduction of fossil fuel subsidies. New policies and regulations may address energy efficiency in appliances, building codes, or rebate programs. In Tanzania, USAID facilitated an IRRP approach with the government to assess the climate risks associated with hydropower facilities given expanding electricity demand, and identify several plausible investment portfolios for the national utility to explore to diversify the energy resource mix.

\section{- Lever Six: Formulation of National} Strategies to Define Climate Finance and Clean Energy Opportunities. Provide support for formulating robust clean energy investment strategies aligned with partner countries' NDCs, and engage extensively with the private sector by hosting forums to garner investment commitments, development of joint solutions, and broad stakeholder cooperation. USAID is working with the Government of Indonesia to mobilize \$5 billion in public and private financing for renewable energy and energy efficiency to advance the national strategy to achieve a net-zeroemissions future.

\section{- Lever Seven: Establishment of} Markets to Capture the Full Value of Clean Energy. Provide technical assistance on market designs that better capture the value of energy efficiency, demand response, and distributed energy resources, such as capacity markets and ancillary service markets. Support markets for carbon bonus and tradable renewable energy certificates (RECs), such as distributed, time-valued, and Peace RECs in fragile, climate-vulnerable settings, that can fill a shortfall in project financing.
Entrepreneur and Financial Innovation Levers

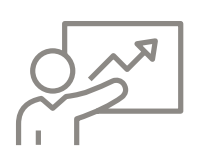

Building capacity in the private and utility sector to catalyze energy sector innovation

Barriers addressed: Significant innovation will be required to meet a net-zero-by-2050 pathway; national development banks and private financing institutions lack capacity and are underused as part of the global climate finance framework; and investors are making poorly informed energy investment decisions that do not necessarily reflect realism in cost/risk assessments.

- Lever Eight: Capacity Development for Entrepreneurs to Drive Technology and Business Model Innovation. Support deployment of integrated clean energy, information technology, and digitalization solutions for small and medium enterprises, and build the capacity of entrepreneurs to adapt and develop clean energy innovations locally. The USAID Development Innovation Ventures team can introduce clean energy entrepreneurship programs, including those that intersect with other sectors, such as agriculture, water, wastewater,

Innovation Highlight: Green Banks

Green banks are usually publicly owned, commercially operated lending institutions that specialize in climatefriendly projects. They can play an important role in leveraging public sector funding to attract private sector capital. USAID could help countries design green banks and partner with foundations and the private sector to provide initial capitalization. Green banks can disperse low-interest loans or grants to small businesses through the bank or provide incentives for adopting energy efficiency technologies at the manufacturer, distributor, or retail level. 


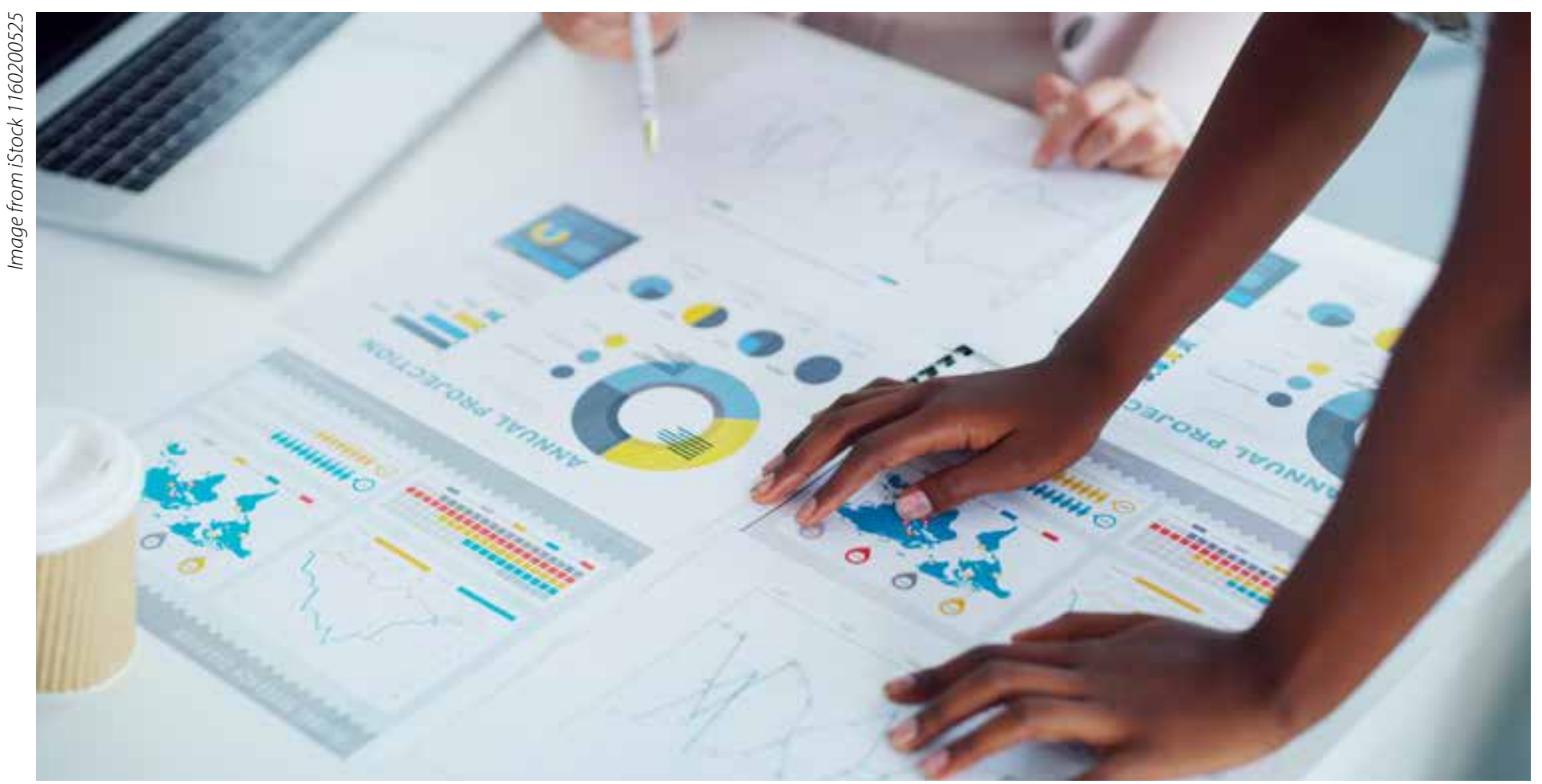

and solid waste. Through the Private Financing Advisory Network (PFAN), USAID supports the identification, financing, and deployment of innovative renewable energy projects by bridging the gap between investors, clean energy entrepreneurs, and project developers.

\section{- Lever Nine: Support to the Financial} Sector to Develop Green Finance Products and Regulations. USAID can expand existing strategic donor partnerships, for example, with the Global Environment Facility and Green Climate Fund. Collaborate with national development banks and commercial banks to improve their access to climate finance resources, ability to design green financing products, and ability to develop related guarantees or clean energy funds. The USAID Climate Economic Analysis for Development, Investment and Resilience (CEADIR) program translated an existing Clean Energy Lending Toolkit into Spanish and French and used it in bank trainings and diagnostics in 14 countries in Central America and Africa. Access to scalable, long-term, low-cost debt capital is critical to the growth of the renewable energy sector and for India to reach its renewable energy goals. From 2013 through 2017, USAID partnered with India's Ministry of New and Renewable Energy to support green bonds as a potential financing solution to address the investment gap in the Indian market. USAID helped build the capacity of local financial institutions, which were critical to green bonds' successful issuance, by introducing Indian project developers and financiers to institutional investors interested in backing their projects. Today, India is the world's secondlargest market for green bonds, with \$28.2 billion worth of bonds issued. The USAID-supported PFAN has worked with the State Energy Agency of Ukraine on the development of a green bonds market and provided technical assistance to help Ukraine encourage banks and investors to finance green projects.

\section{- Lever Ten: Provision of Data,} Information, and Analysis to Inform Climate Risk-Averse Investment. USAID can undertake assessments to address the deficit of localized data on the viability and cost of fossil fuels versus clean energy technologies. Present data modeling and visualizations that communicate the potential for early coal plant retirement, returns on replacement and new clean energy investments, and the associated benefits from job growth. The Greening the Grid platform, managed through the USAID-NREL Partnership, includes information and guidance to support countries in power system transformation and grid modernization.

\section{Projecting Outlays}

NREL developed an impact projection tool to measure potential outlays of enacting any of the 10 climate finance for clean energy and energy efficiency levers. In this high-level table, the costs, risk, and impacts are only assessed qualitatively relative to the other respective levers; more refined inputs would be necessary to conduct a quantitative assessment of specific interventions. The key takeaway is that the different levers each have unique strengths that can be combined into comprehensive packages for diverse 
impacts, depending on the needs of the individual partner country USAID is supporting.

The first two categories in the assessment tool are Cost and Risk. "Low-cost" interventions are those estimated to be less than $\$ 5$ million to implement; "moderate cost" is \$5-\$15 million; and "high cost" is $\$ 15+$ million. The costs are based on expected investments required for large country or regional programs for groups of smaller countries; actual funding needs would require more detailed analysis. The risk rating reflects the uncertainty that a program will have the intended impacts and/or be an effective use of capital. Risk is not necessarily negative. USAID could ideally support some riskier, emerging technology solutions or markets that are unlikely to attract private sector investments - if they are projected to potentially have a significant positive impact. The remaining five categories assess the possible benefits in the form of near-term GHG Reduction; Investment

Mobilization that moves downstream; Innovation in technologies, services, or business models; Job Creation from direct employment or resulting from USAID technical assistance; and Social Impacts related to gender, energy access, just transition, and social equity.

\section{Acknowledgments}

This brief is adapted from a full technical report authored by Bethany Speer and Kevin Wu (NREL). Moriah Petty, Isabel McCan, and Karen Petersen (NREL) provided editorial support, and Christopher Schwing (NREL) provided design support. Thanks also goes to Jeremy Foster and Sarah Lawson (USAID), and Alexandra Aznar (NREL), for their review and guidance.

High-level, Qualitative Assessment of the 10 Clean Energy Investment Mobilization Levers

\begin{tabular}{|c|c|c|c|c|c|c|c|}
\hline \multirow[b]{2}{*}{ Lever } & \multirow{2}{*}{$\begin{array}{l}\text { Program } \\
\text { Cost }\end{array}$} & \multirow[b]{2}{*}{ Risk Taking } & \multicolumn{5}{|c|}{ Potential Impacts (Qualitative Assessments) } \\
\hline & & & $\begin{array}{l}\text { GHG } \\
\text { Reduction }\end{array}$ & $\begin{array}{l}\text { Investment } \\
\text { Mobilization }\end{array}$ & Innovation & Job Creation & $\begin{array}{l}\text { Social } \\
\text { Impacts }\end{array}$ \\
\hline $\begin{array}{l}\text { 1: Blended Finance To Catalyze Projects and Companies and } \\
\text { Provide Utility Refinancing }\end{array}$ & $\mathrm{H}$ & $\mathrm{H}$ & $\mathrm{H}$ & $\mathrm{H}$ & $\mathrm{L}$ & $\mathrm{M}$ & M \\
\hline $\begin{array}{l}\text { 2: Capacity Development To Scale Project Pipelines and } \\
\text { Improve Access to Climate Finance }\end{array}$ & $M$ & $M$ & L-M & $M$ & $\mathrm{~L}$ & $\mathrm{~L}$ & M \\
\hline $\begin{array}{l}\text { 3: Contract Standardization and Support for Securitization } \\
\text { To Increase Liquidity }\end{array}$ & $\mathrm{L}$ & $M$ & $\mathrm{~L}$ & $\mathrm{H}$ & $M$ & $\mathrm{~L}$ & $\mathrm{~L}$ \\
\hline $\begin{array}{l}\text { 4: Development of Public and Infrastructure Investments for } \\
\text { Sustained Growth }\end{array}$ & $M$ & $\mathrm{~L}$ & $\mathrm{M}-\mathrm{H}$ & $\mathrm{H}$ & $\mathrm{M}-\mathrm{H}$ & $\mathrm{M}-\mathrm{H}$ & $M$ \\
\hline $\begin{array}{l}\text { 5: Improvements to Enabling Environments To Attract Long- } \\
\text { term Investments }\end{array}$ & $M$ & $\mathrm{~L}$ & $\mathrm{M}-\mathrm{H}$ & $M$ & $\mathrm{M}-\mathrm{H}$ & $\mathrm{M}-\mathrm{H}$ & $M$ \\
\hline $\begin{array}{l}\text { 6: Formulation of National Strategies To Define Climate } \\
\text { Finance and Clean Energy Opportunities }\end{array}$ & $M$ & $\mathrm{~L}$ & $\mathrm{M}-\mathrm{H}$ & $\mathrm{H}$ & $\mathrm{M}-\mathrm{H}$ & $\mathrm{M}-\mathrm{H}$ & M \\
\hline $\begin{array}{l}\text { 7: Establishment of Markets To Capture the Full Value of } \\
\text { Clean Energy }\end{array}$ & $\mathrm{L}$ & $M$ & $\mathrm{~L}$ & $\mathrm{~L}$ & $M$ & $\mathrm{~L}$ & L-M \\
\hline $\begin{array}{l}\text { 8. Capacity Development for Entrepreneurs To Drive } \\
\text { Technology and Business Innovation }\end{array}$ & $\mathrm{M}-\mathrm{H}$ & $\mathrm{H}$ & $\mathrm{L}$ & $M$ & $\mathrm{H}$ & $\mathrm{L}$ & $\mathrm{H}$ \\
\hline $\begin{array}{l}\text { 9: Support to the Financial Sector To Develop Green Finance } \\
\text { Products and Regulations }\end{array}$ & $\mathrm{M}-\mathrm{H}$ & $M$ & $\mathrm{~L}$ & $M$ & L-M & $\mathrm{L}$ & $M$ \\
\hline $\begin{array}{l}\text { 10: Provision of Data, Information, and Analysis To Inform } \\
\text { Climate Risk-Averse Investment }\end{array}$ & $\mathrm{L}$ & $M$ & M & M & $\mathrm{L}$ & $\mathrm{L}$ & $\mathrm{L}$ \\
\hline
\end{tabular}

\section{www.nrel.gov/usaid partnership}

This work was authored, in part, by the National Renewable Energy Laboratory (NREL), operated by Alliance for Sustainable Energy, LLC, for the U.S. Department of Energy (DOE) under Contract No. DE-AC36-08GO28308. Funding provided by the United States Agency for International Development (USAID) under Contract No. IAG-17-2050. The views expressed in this report do not necessarily represent the views of the DOE or the U.S. Government, or any agency thereof, including USAID.
The USAID-NREL Partnership addresses critical challenges to scaling up advanced energy systems through global tools and technical assistance, including the Renewable Energy Data Explorer, Greening the Grid, the International Jobs and Economic Development Impacts tool, and the Resilient Energy Platform. More information can be found at: www.nrel.gov/usaid-partnership.

\section{(:) USAID RNREL}

